\title{
Evaluation of buffy coat $16 S$ rRNA PCR, buffy coat culture and whole blood PCR for detection of bacteraemia
}

\author{
Demetrio L Valle Jr ${ }^{1,2,3}$, Jeannie I Andrade ${ }^{3}$, Esperanza C Cabrera ${ }^{4}$, Windell L Rivera ${ }^{2,5 /+}$ \\ ${ }^{1}$ Department of Laboratories, Ospital ng Makati, Makati City, Philippines ${ }^{2}$ Institute of Biology, College of Science ${ }^{5}$ Natural Sciences \\ Research Institute, University of the Philippines, Diliman, Quezon City, Philippines ${ }^{3}$ Department of Pathology, Makati Medical Center, \\ Makati City, Philippines ${ }^{4}$ Biology Department, De La Salle University, Manila, Philippines
}

The use of Gram type-specific PCR on buffy coat from clinical specimens for the detection of bacteraemia was evaluated for the first time using whole blood culture as the gold standard. In addition, the established buffy coat culture and whole blood PCR were also compared. Gram-positive bacteria belonging to six species and Gramnegative bacteria from 10 species were isolated and identified by culture and detected using broad-range 16S rDNA primers and Gram-specific primers. Data from the three methods all conferred very high sensitivity, specificity, positive and negative predictive values when compared to whole blood culture. The Kappa coefficients of agreement were 0.9819 (buffy coat PCR), 0.9458 (whole blood PCR) and 1.0 (buffy coat culture), which establishes their validity as alternative methods to routine blood culture in detecting bacteraemia. In addition, results showed that there was a direct correlation of WBC counts greater than 12,000 cells per $\mathrm{mm}^{3}$ to the occurrence of bacteraemia as detected by the four methods $(p<0.05)$.

Key words: bacteraemia - buffy coat culture - leukocyte count - PCR - blood culture

The incidence of bacteraemia has increased over the past decades and generally is caused by post-operative complications, intravascular catheters and complicated, localised infections (Odetola et al. 2003, Gura 2004). It has an overall in-patient mortality of $20 \%$ which can reach $90 \%$ in patients with septic shock and organ failure (Segal \& Chamberlain 2000, Bearman \& Wenzel 2005). Early detection and appropriate antibiotic treatment are essential for increasing the survival rate of patients (Parker \& Parrillo 1983). Differentiating between Gram-positive and Gram-negative bacteria is one of the most important factors when choosing proper antibiotics (Murty \& Gyaneshwari 2007).

Blood culture is one of the most sensitive procedures for detecting bacteria (Shafazand \& Weinacker 2002). However, the assay requires incubation, subculturing and biochemical and/or immunologic tests to identify the bacterium. Molecular assays based on nucleic acids have been shown to have greater sensitivity and specificity in numerous studies in the identification of bacteria, fungi and viruses in different clinical samples (Greisen et al. 1994, Klausegger et al. 1999, Caliendo et al. 2002, Varghese et al. 2006, Klouche \& Schröder 2008). Unlike blood culture, nucleic acid-based assays do not require growth of an organism for detection, are proven sensitive in diagnosing nonculturable pathogens and have a shorter turnaround time (Greisen et al. 1994, Klausegger et al. 1999, Klouche \& Schröder 2008, Madico \& Rice 2008).

Financial support: Philippine Council for Health Research and Development (to DLV Jr), Natural Sciences Research Institute of the University of the Philippines-Diliman (to WLR)

+Corresponding author: wlrivera@science.upd.edu.ph

Received 25 May 2009

Accepted 3 February 2010
Universal primers targeting the 16S rRNA gene in bacteria have been used in the identification of a wide range of bacterial pathogens in blood, cerebrospinal fluid (CSF) and other normally sterile body fluids (Klausegger et al. 1999, Jordan \& Durso 2000, Xu et al. 2005). Klausegger et al. (1999) studied the use of Gram typespecific PCR for differentiating a wide range of pathogenic Gram-positive and Gram-negative bacteria in pure bacterial isolates from whole blood, sputum and CSF. Gram type-specific broad range PCR correctly classified all 62 pathogenic species tested.

No study has yet been made on the use of broad range Gram type-specific PCR on buffy coat samples for the rapid detection of bacteraemia. Blood culture would not be made obsolete by this method because pure isolates are required for antimicrobial drug susceptibility testing. However, if a PCR-based test could unfailingly rule out bacteraemia faster than blood culture, it will allow prompt treatment of patients with true infections; thus reducing the mortality rate and overall health care costs.

The main objective of this paper was to compare the bacteraemia-detecting capabilities of PCR of buffy coat, culture buffy coat and PCR of whole blood with the gold standard, whole blood culture, for the detection of bacteremia. The sensitivity, specificity, positive predictive value (PPV) and negative predictive value (NPV) of the three methods were determined. In addition, the white blood cells (WBC) count of samples was measured to determine if it is directly correlated with the occurrence of bacteraemia as determined by all four methods.

\section{PATIENTS, MATERIALS AND METHODS}

Patient selection, specimen collection and preparation - The Ospital ng Makati is a fully integrated, government-funded health system that provides virtually all medical and surgical care to the residents of the city of Makati and nearby towns in the Philippines. Approval 
for the study was granted by the hospital's Institutional Review Board. This study included all specimens submitted for blood culture testing from the emergency room and in-patients from October 1, 2007-December 31, 2007 and from August 25, 2008-October 8, 2008. Inclusion criteria were adult patients with at least two of the following clinical signs and symptoms of sepsis: temperature $>38^{\circ} \mathrm{C}$ or $<36^{\circ} \mathrm{C}$, heart rate $>90$ beats per min, respiratory rate $>20$ breaths per min or $\mathrm{PaCO}_{2}<$ $32 \mathrm{~mm} \mathrm{Hg}$, leukocyte count $>12,000$ cells per $\mathrm{mm}^{3},<$ 4,000 cells per $\mathrm{mm}^{3}$ or $>10 \%$ immature (band) forms (Bone et al. 1992). Sample rejection or exclusion criteria were as follows: paediatric patients, patients receiving antimicrobial treatment for more than $48 \mathrm{~h}$ and patients without signs and symptoms of sepsis. Each of the 114 qualified patients was sampled once. The blood extraction of the patients was performed by medical technologists of the Department of Laboratories. Ten millilitres of extracted blood was inoculated into both aerobic and anaerobic blood culture bottles (BacT/ALERT FA \& FAN, bioMérieux, Marcy l'Etoile, France) and $5 \mathrm{~mL}$ of blood into each of two sterile EDTA-treated tubes (Terumo, Japan). The blood culture bottles were gently rotated to mix the blood and the broth. The blood specimens in the EDTA-treated tubes were also mixed well by inverting 8-10 times. One tube was processed for buffy coat culture as follows. The tube was centrifuged at $2,500 \mathrm{~g}$ for $10 \mathrm{~min}$ at RT. Three hundred $\mu \mathrm{L}$ of buffy coat was extracted using a sterile syringe and immediately inoculated into a blood culture bottle (BacT/ALERT FA, bioMérieux, Marcy l'Etoile, France). Due to the limited quantity of the buffy coat, culture for obligate anaerobes was not carried out. The other tube was processed for buffy coat PCR and for whole blood PCR as follows. Using a sterile syringe, $1 \mathrm{~mL}$ of whole blood was separated, placed in a sterile microfuge tube and stored at $-20^{\circ} \mathrm{C}$ until used for DNA extraction and PCR analysis of whole blood. For buffy coat preparation, the extracted buffy coat was washed with molecular grade phosphate-buffered saline and reconstituted to $2.0 \mathrm{McFarland}$ standard opacity. The resultant suspension was stored in a sterile microfuge tube and frozen until use.

Whole blood culture and buffy coat culture processing - The inoculated culture bottles that were inoculated with whole blood or buffy coat were incubated at $37^{\circ} \mathrm{C}$ for at most five days. BacT/ALERT FA and BacT/ALERT FAN are for aerobic and anaerobic cultures, respectively. Only BacT/ALERT FA was used for buffy coat culture due to limited amount of sample. Samples that were positive were inoculated to produce a pure culture on blood agar (Merck), MacConkey agar (Merck) and chocolate agar. Appropriate biochemical tests were performed for the identification of the species using VITEK system (bioMérieux, Marcy l'Etoile, France). The culture bottles that did not show any sign of bacterial growth after five days of incubation were reported as negative.

Bacterial DNA extraction - Bacterial genomic DNA was extracted using QIAamp DNA blood mini kit (Qiagen, Germany) following the manufacturer's protocol. The resultant DNA extract was frozen at $-20^{\circ} \mathrm{C}$ until use.
PCR and agarose gel electrophoresis - For PCR analysis, $1 \mu \mathrm{L}$ of each prepared specimen was added to $49 \mu \mathrm{L}$ of a PCR master mix (New England Biolabs, Inc, USA) consisting of $1 \mathrm{X}$ Standard Taq Reaction Buffer $\left(10 \mathrm{mM}\right.$ Tris- $\mathrm{HCl} \mathrm{pH} 8.3$ at $25^{\circ} \mathrm{C}, 50 \mathrm{mM} \mathrm{KCl}, 1.5 \mathrm{mM}$ $\mathrm{MgCl}_{2}$ ), $200 \mu \mathrm{M}$ deoxynucleotide solution mix, 0.02 unit/ $\mu \mathrm{L}$ Taq DNA polymerase and $0.5 \mu \mathrm{M}$ of each primer. Universal broad-range PCR was carried out with the primers DG74 (5'-AGGAGGTGATCCAACCGCA-3') and 65ab (5'-AACTGGAGGAAGGTGGGGAY-3'); Gram-positive-specific PCR was carried out with the primers DG74 and 143 (5'-GAYGACGTCAARTCMTCATGC-3'); and Gram-negative-specific PCR was carried out using the primers DG74 and 68d (5'-AYGACGTCAAGTCMTCATGG-3') (Greisen et al. 1994, Klausegger et al. 1999). The initial denaturation was done at $95^{\circ} \mathrm{C}$ for $5 \mathrm{~min}$ and was followed by 30 cycles of denaturation at $95^{\circ} \mathrm{C}$ for $30 \mathrm{sec}$, annealing at $65^{\circ} \mathrm{C}$ for 30 sec and extension at $72^{\circ} \mathrm{C}$ for $2 \mathrm{~min}$. The final extension step was done at $72^{\circ} \mathrm{C}$ for $5 \mathrm{~min}$. Universal broad range PCR primers were initially used on the whole blood and buffy coat specimens. The expected amplicons were 400 bp. Specimens with negative results were repeated twice. Specimens with positive results were further subjected to Gram speciation, using Gram-type specific primers to identify Gram-positive and Gram-negative bacteria. Both sets of primers yielded amplicons of $400 \mathrm{bp}$.

Controls for buffy coat and whole blood PCR - For positive controls, blood from a healthy person was separately inoculated with two pure colonies each of Staphylococcus aureus and Escherichia coli. The tubes were incubated for $2 \mathrm{~h}$ at RT and specimens for whole blood and buffy coat PCR were processed as described earlier. Likewise, blood from the healthy individual was used as the negative control.

PCR was also carried out on whole blood and buffy coat specimens using primers for the human $\beta$-globin gene. This served as an internal control to rule out the presence of PCR inhibitors. The reaction mixture consisted of 1X PCR buffer, $1.5 \mathrm{mM} \mathrm{MgCl}, 200 \mu \mathrm{M}$ deoxynucleotide mix, 0.02 units/ $\mu \mathrm{L}$ Taq DNA polymerase, $0.5 \mu \mathrm{M}$ each of BGF (5'-GCCAGTGCCAGAAGAGCCAA-3') and BGR (5'-TTAGGGTTGCCCATAACAGC-3') primers (Murdoch et al. 2003) and DNA template. The PCR conditions were as follows: an initial denaturation at $95^{\circ} \mathrm{C}$ for $5 \mathrm{~min}$, followed by 30 cycles of $95^{\circ} \mathrm{C}$ for $30 \mathrm{sec}, 55^{\circ} \mathrm{C}$ for $30 \mathrm{sec}, 72^{\circ} \mathrm{C}$ for $1 \mathrm{~min}$ and final extension at $72^{\circ} \mathrm{C}$ for $5 \mathrm{~min}$. The expected amplicons were $500 \mathrm{bp}$ in size.

The products, together with controls and 2-Log DNA ladder were resolved by electrophoresis at $100 \mathrm{~V}$ for 45 $\min$ in a $2 \%$ agarose gel. The DNA bands were visualised with an ultraviolet transilluminator after staining with ethidium bromide.

Statistical analysis - The Kappa coefficient was used to determine the agreement between the gold standard, whole blood culture and buffy coat PCR, buffy coat culture or whole blood PCR. A Kappa coefficient of 0.8-1.0 indicates a very good agreement between the methods. The association between the patient's WBC count, classi- 
fied as $>12,000$ cells per $\mathrm{mm}^{3}$ or $<12,000$ cells per $\mathrm{mm}^{3}$ and test results was determined using the Chi-square test. $\mathrm{P}$ values less than 0.05 were considered significant and indicate that there was a direct correlation between the WBC count and bacteraemia test results.

\section{RESULTS}

Study population - A total of 114 patients admitted to the Ospital ng Makati within the periods of October 1, 2007-December 31, 2007 and August 25, 2008-October 8,2008 , fulfilled the criteria for sepsis and were included in the study. The study population consisted of $52(45.6 \%)$ males and $62(54.4 \%)$ females, with ages ranging from 18-91 (mean of 53.8). Evaluation of the vital signs comprising the inclusion criteria showed that the body temperature of the study population ranged from $37.4-39.2^{\circ} \mathrm{C}$ (mean of $38.22^{\circ} \mathrm{C}$ ). Cardiac rates ranged from $84-106$ beats per minute (mean of 95 beats/minute). Respiratory rates obtained were 19-36 cycles/minute (mean of $26.7 \mathrm{cy}$ cles/minute). The leukocyte counts of the patients ranged from 3,658-26,341 per $\mathrm{mm}^{3}$ (mean of 14,646/ $\mathrm{mm}^{3}$ ).

Whole blood culture - Forty-eight out of the 114 whole blood samples (or 42.1\%) were positive for bacterial growth as detected by BacT/Alert and identified using the VITEK system. Each sample corresponded to a different patient and yielded only one microbial species. Twenty-one of the 48 specimens $(44 \%)$ were from patients admitted in the intensive care unit (ICU), 15 (31\%) were from the medicine ward, eight $(17 \%)$ were from the private rooms and one $(2 \%)$ each were from the obstetrics ward, gynaecology ward, ear nose throat ward and the emergency room. Twenty-two (46\%) were from male patients and $26(54 \%)$ were from female patients, with ages ranging from 18-78 years (mean of 51).

Of the 48 bacteria isolated, 21\% were Gram-positive and $79 \%$ were Gram-negative. Six species of Grampositive and 10 species of Gram-negative bacteria were identified (Table I). The most frequently isolated species was Burkholderia cepacia at $27 \%$, followed by E. coli at $12.5 \%$ and Klebsiella pneumoniae and S. aureus at $10.4 \%$ each. Table II shows the identity of the isolated organism from each specimen.

Comparison of buffy coat PCR with whole blood culture - The buffy coat PCR showed that 47 of the 114 specimens (or $41.2 \%$ ) were positive as compared to the 48 (42.1\%) positive obtained with the whole blood culture. The Gram-positive bacterium Peptostreptococcus magnus was not detected (Table II). The Kappa coefficient of 0.9819 shows very good agreement and suggests that the buffy coat PCR can be used as an alternative method to whole blood culture for the diagnosis of bacteraemia. The specificity (100\%), sensitivity (97.1\%), PPV (100\%) and NPV (98.5\%) for this method are very high. Figure shows the amplicons of some of the specimens using the universal primers, Gram-specific primers and human $\beta$-globin positive control primers.

Comparison of buffy coat culture with whole blood culture - Buffy coat culture showed that $47(41.2 \%)$ of the specimens were positive for bacterial growth. The obligate anaerobe P. magnus, which was detected in the whole blood sample, could not be detected in the buffy coat due to the lack of specimen for anaerobic culture. The results of the aerobic cultures using whole blood and buffy coat were identical, identifying the same Gram-positive and Gram-negative bacteria (Table II). The Kappa coefficient of 1.0 shows complete agreement between the two methods and affirms that buffy coat culture can be used as an alternative method for routine whole blood culture. Compared to the gold standard of whole blood culture, the specificity, sensitivity, PPV and NPV of buffy coat culture were $100 \%$.

\section{TABLE I}

Percent occurrence of bacteria identified from bacteremic patients

\begin{tabular}{lc}
\hline & Occurrence \\
Bacterial species & $\%$ \\
\hline Gram-negative & 27 \\
Burkholderia cepacia & 12.5 \\
Escherichia coli & 10.4 \\
Klebsiella pneumoniae & 8.3 \\
Pseudomonas aeruginosa & 6.3 \\
Proteus mirabilis & 4.2 \\
Serratia marcescens & 4.2 \\
Salmonella typhi & 2 \\
Acinetobacter baumannii & 2 \\
Enterobacter cloacae & 2 \\
Chrysomonas luteola & \\
Gram-positive & 10.4 \\
Staphylococcus aureus & 2 \\
Streptococcus agalactiae & 2 \\
Staphylococcus epidermidis & 2 \\
Viridans streptococi & 2 \\
Peptostreptococcus magnus & 2 \\
Enterococcus faecalis & \\
\hline
\end{tabular}

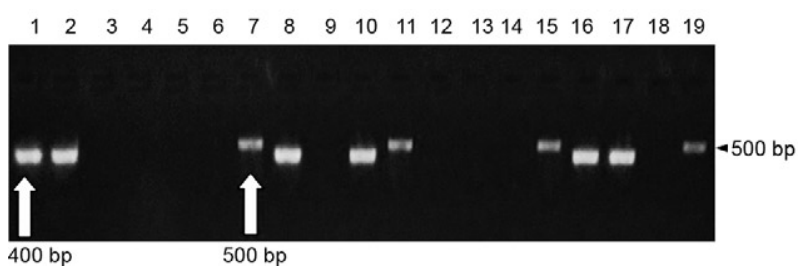

PCR amplicons from buffy coat of bacteremic and non-bacteremic patients. With broad range 16s rDNA primers (400 bp): 1: Staphylococcus aureus positive control; 2: Escherichia coli positive control; 3: negative control from healthy volunteer; 4 : negative result in PCR and culture from patient $1 ; 8$ : positive result from patient $2 ; 12$ : negative result in PCR and culture from patient 3; 16: positive result from patient 4 . With Gram positive specific primers (400 bp): 5: negative result in PCR and culture from patient 1; 9: negative result from patient 2; 13: negative result from patient 3; 17: patient 4 with Gram-positive isolate. With Gram-negative specific primers $(400 \mathrm{bp})$ : 6 : negative result in PCR and culture from patient 1; 10: patient 2 with Gramnegative isolate; 14: negative result in PCR and culture from patient 3; 18: negative result from patient 4 . With primers for internal control $\beta$-globin gene: 7, 11, 15, 19 showing $500 \mathrm{bp}$ amplicons. 
TABLE II

Summary of specimens with positive culture and PCR results

\begin{tabular}{|c|c|c|c|c|c|}
\hline Sample & $\begin{array}{l}\text { Bacti-alert } \\
\text { day positive }\end{array}$ & $\begin{array}{l}\text { Whole blood aerobic, } \\
\text { anaerobic culture }\end{array}$ & $\begin{array}{c}\text { Buffy coat } \\
\text { aerobic culture }\end{array}$ & $\begin{array}{c}\text { Whole blood } \\
\text { PCR } \\
\text { (universal) }\end{array}$ & $\begin{array}{c}\text { Buffy coat } \\
\text { PCR } \\
\text { (universal) }\end{array}$ \\
\hline 33,54, & $1 \mathrm{st}$ & Burkholderia cepacia & B. cepacia & positive & positive \\
\hline $16,18,37,41,59$ & 2nd & B. cepacia & B. cepacia & positive & positive \\
\hline $28,34,60,67,81,94$ & $3 \mathrm{rd}$ & B. cepacia & B. cepacia & positive & positive \\
\hline 22 & $3 \mathrm{rd}$ & Chrysomonas luteola & C. luteola & positive & positive \\
\hline 25 & $1 \mathrm{st}$ & Escherichia coli & E. coli & positive & positive \\
\hline 69,97 & 2nd & E. coli & E. coli & positive & positive \\
\hline $101,104,113$ & $3 \mathrm{rd}$ & E. coli & E. coli & positive & positive \\
\hline 31 & 5 th & Peptostreptococcus magnus & Anaerobic culture not done & negative & negative \\
\hline 36 & 4th & Streptococcus agalactiae & S. agalactiae & positive & positive \\
\hline $40,43,80,95$ & $3 \mathrm{rd}$ & Staphylococcus aureus & S. aureus & positive & positive \\
\hline 110 & 4 th & S. aureus & S. aureus & positive & positive \\
\hline 91 & 2nd & Staphylococcus epidermidis & S. epidermidis & positive & positive \\
\hline 42 & 4 th & Enterobacter cloacae & E. cloacae & negative & positive \\
\hline $51,70,92,99$ & 2nd & Klebsiella pneumonia & K. pneumonia & positive & positive \\
\hline 109 & $3 \mathrm{rd}$ & K. pneumoniae & K. pneumoniae & positive & positive \\
\hline 58 & 4 th & Viridans streptococci & $V$. streptococci & positive & positive \\
\hline 68 & 2nd & Acinetobacter baumannii & A. baumannii & negative & positive \\
\hline 82,111 & 2nd & Salmonella typhi & S. typhi & positive & positive \\
\hline 87,114 & 2nd & Serratia marcescens & S. marcescens & positive & positive \\
\hline 88,102 & 2nd & Proteus mirabilis & P. mirabilis & positive & positive \\
\hline 98 & $3 \mathrm{rd}$ & P. mirabilis & P. mirabilis & positive & positive \\
\hline $84,96,100,103$ & 2nd & Pseudomonas aeruginosa & P. aeruginosa & positive & positive \\
\hline 107 & 2nd & Enterococcus faecalis & E. faecalis & positive & positive \\
\hline
\end{tabular}

Comparison of whole blood PCR with whole blood culture - Forty-five of the 114 specimens (or 39.5\%) were positive for the presence of bacteria (Table II). Enterobacter cloacae, Acinetobacter baumannii and $P$. magnus from three specimens that were detected in the whole blood and buffy coat cultures were not detected using whole blood PCR. The internal controls for the human $\beta$-globin gene did not produce amplicons either in these samples, which suggest the presence of certain inhibitory factors in the whole blood. The Kappa coefficient was 0.9458 , which still shows very good agreement and indicates that whole blood PCR can be utilised as an alternative method to whole blood culture for the detection of bacteraemia. The method showed very high specificity (100\%), sensitivity (93.75\%), PPV (100\%) and NPV (95.65\%).

Leukocyte count in association with whole blood culture, whole blood PCR, buffy coat culture and buffy coat $P C R$ - The average leukocyte count obtained in blood culture specimens with positive bacteraemia results was $16,550 / \mathrm{mm}^{3}$. To determine if the leukocyte count correlated with results from the four methods, a standard level of $12,000 / \mathrm{mm}^{3}$ was set as the threshold for systemic inflammatory response (Bone et al. 1992). All of the methods utilised demonstrated that specimens with a WBC count of $<12,000 / \mathrm{mm}^{3}$ were negative for microbial growth, while those with a WBC count of $>12,000$ / $\mathrm{mm}^{3}$ had either a positive or negative result. Chi-square analysis showed a $\mathrm{p}$ value of less than 0.05 and substantiates the significance of the WBC count as a basis for comparing bacteraemia detection results from whole blood culture, whole blood PCR, buffy coat culture or buffy coat PCR.

\section{DISCUSSION}

In the diagnosis of bacteraemia, defined as the presence of viable bacteria in circulating blood, whole blood culture has been considered the gold standard for many years (Shafazand \& Weinacker 2002). Blood culture allows the identification of the causative organism and, when combined with antibiotic susceptibility testing, can provide information to the physician regarding the best antibiotic therapy.

The volume of blood withdrawn for culture is an important variable when detecting microorganisms in the blood of bacteremic patients. This study used only $5 \mathrm{~mL}$ of blood for buffy coat culture, which is in contrast the $10 \mathrm{~mL}$ of blood used for both aerobic and anaerobic whole blood cultures. The smaller volume was used to determine feasibility for alternative cases, such as paediatric and geriatric patients, where the blood volume is not enough for the routinely used culture bottles. All of the microorganisms isolated and identified using the buffy coat culture method concurred with the results of the whole blood culture, which makes the smaller volume a promising alternative for blood culture. The high 
sensitivity (100\%), specificity (100\%), PPV (100\%) and NPV (100\%) support its utilisation as an alternative culture method. Documented studies on the use of the buffy coat for culture are rare, further adding to the value of this study.

Although whole blood and buffy coat culture present many advantages and high accuracy, for sepsis or other life-threatening infectious cases there is no question that a more rapid diagnostic method is preferable. Culture takes a minimum of three days to complete, depending on how fast the microorganism grows. Serologic methods, erythrocyte sedimentation rate and buffy coat direct microscopy method are currently employed in the clinical laboratory for the rapid diagnosis of bacteraemia. Nonetheless, these methods present varying degrees of sensitivity, which are considered acceptable but not superior enough. Compared to the whole blood and buffy coat PCR evaluated in this study, the aforementioned methods appear to be less sensitive and less specific.

With the whole blood PCR, microorganisms from three samples, identified as E. cloacae, A. baumannii and $P$. magnus using whole blood culture, were not detected; in contrast, buffy coat PCR failed to detect only P. magnus. The sensitivity (93.75\%) and NPV (95.65\%) of whole blood PCR, though high, were lower than those for buffy coat PCR (which were $97.1 \%$ and $98.5 \%$, respectively). The internal controls for the amplification of the $\beta$-globin gene also did not produce amplicons in those whole blood samples, suggesting the presence of certain inhibitory factors in the specimens. Mitka et al. (2007) also showed that whole blood PCR was slightly less sensitive than buffy coat PCR for detecting Brucella melitensis. $\mathrm{Ng}$ et al. (2008) demonstrated that buffy coat PCR was more sensitive than PCR of plasma and blood culture for invasive pneumococcal disease and remained positive for the majority of the test animals for at least 48 $\mathrm{h}$ after start of antibiotic therapy.

The inability of whole blood PCR to identify certain species could be attributed to the inhibitory effect on PCR of substances such as haemoglobin (de Vries et al. 2001), immunoglobulin G (Al-Soud et al. 2000) and anticoagulant (Morata et al. 1998) in the whole blood samples and not in buffy coat. The results suggest buffy coat PCR is reliable for detecting bacteraemia and determining Gram reactivity of bacteria. Patients can then be treated promptly with empirical antibiotics once the microorganism is determined as being Gram-positive or Gram-negative. However, buffy coat PCR cannot, at present, be solely requested since it cannot parallel the value of the routine blood culture in terms of species isolation, identification and antimicrobial susceptibility testing, particularly in cases of multi-drug resistant bacteria, wherein empirical antibiotic therapy is not feasible.

A significant finding of this study was the detection of $B$. cepacia as a major cause of nosocomial bacteraemia, particularly in the ICU. $B$. (previously known as Pseudomonas) cepacia, a nutritionally versatile, Gramnegative organism, was first described in 1949 by Walter Burkholder of Cornell University, as the phytopathogen responsible for a bacterial rot of onions (Burkholder 1950) and was first reported as a human pathogen caus- ing endocarditis in the 1950s (Holmes et al. 1998). The organism has a particular predilection for the lung in patients with cystic fibrosis and has emerged as an important opportunistic human pathogen in hospitalised and immunocompromised patients (Thomassen et al. 1985). Since then, the organism has caused numerous catheterassociated urinary tract infections, wound infections and intravenous catheter-associated bacteraemia. The high occurrence of B. cepacia infection among the bacteremic patients in the present study reflects the persistence and transmissibility of the organism, especially among the vulnerable patients such as those in the ICU (Matrician et al. 1998, Loukil et al. 2003), where 54\% of the patients positive for this organism were confined. B. cepacia has been found to survive for 68 weeks in commercially manufactured povidone-iodine (Anderson et al. 1990). It has also been reported in nosocomial outbreaks involving respirator equipment (Weems 1990), parenteral solutions (Doit et al. 2004) and nebuliser solutions (Hamill et al. 1995) among others.

The WBC count has been the most widely studied laboratory parameter in occult bacteraemia and has been observed to consistently increase in patients with bacterial sepsis. With regard to the correlation of the leukocyte count with sepsis, there are no definite records as to how high the leukocyte count should be to obtain a positive blood culture or PCR. A patient can have leukopenia, yet show bacteraemia and a patient can have leukocytosis without bacteraemia. The findings of the study showed the direct correlation of WBC counts of $>12,000 / \mathrm{mm}^{3}$ to the occurrence of bacteraemia. All of the methods utilised demonstrated that specimens with a WBC count of $<12,000 / \mathrm{mm}^{3}$ were negative for microbial growth whereas those with a WBC count of $>12,000 /$ $\mathrm{mm}^{3}$ had either positive or negative results.

In conclusion, buffy coat PCR, buffy coat culture and whole blood PCR can be used as alternative methods to whole blood culture in detecting bacteraemia, with buffy coat culture showing $100 \%$ agreement with whole blood culture and buffy coat PCR showing higher sensitivity and NPV than whole blood PCR. In addition, there is direct correlation of WBC counts of $>12,000 / \mathrm{mm}^{3}$ to the occurrence of bacteraemia.

\section{REFERENCES}

Al-Soud WA, Jonsson LJ, Radsstrom P 2000. Identification and characterization of immunoglobulin $\mathrm{G}$ in blood as a major inhibitor of diagnostic PCR. J Clin Microbiol 38: 345-350.

Anderson RL, Vess RW, Panlilio AL, Favero MS 1990. Prolonged survival of Pseudomonas cepacia in commercially manufactured povidone-iodine. Appl Environ Microbiol 56: 3598-3600.

Bearman GM, Wenzel RP 2005. Bacteremias: a leading cause of death. Arch Med Res 36: 646-659.

Bone RC, Balk RA, Cerra FB, Dellinger RP, Fein AM, Knaus WA, Schein RM, Sibbald WJ 1992. Definitions for sepsis and organ failure and guidelines for the use of innovative therapies in sepsis. The ACCP/SCCM Consensus Conference Committee. American College of Chest Physicians/Society of Critical Care Medicine. Chest 101: 1644-1655.

Burkholder W 1950. Sour skin, a bacterial rot of onion bulbs. Phytopathology 40: 115-118. 
Caliendo AM, St. George K, Allega J, Bullotta AC, Gilbane L, Rinaldo CR 2002. Distinguishing cytomegalovirus (CMV) infection and disease with CMV nucleic acid assays. J Clin Microbiol 40: $1581-1586$

de Vries JE, Wijnen PA, Hamulyak K, van Dieijen-Visser MP, Bekers O 2001. PCR on cell lysates obtained from whole blood circumvents DNA isolation. Clin Chem 47: 1701-1702.

Doit C, Loukil C, Simon AM, Ferroni A, Fontan JE, Bonacorsi S, Bidet P, Jarlier V, Aujard Y, Beaufils F, Bingen E 2004. Outbreak of Burkholderia cepacia bacteremia in a pediatric hospital due to contamination of lipid emulsion stoppers. $J$ Clin Microbiol 42: 2227-2230.

Greisen K, Loeffelholz M, Purohit A, Leong D 1994. PCR primers and probes for the 16S rRNA gene of most species of pathogenic bacteria, including bacteria found in cerebrospinal fluid. $J$ Clin Microbiol 32: 335-351.

Gura KM 2004. Incidence and nature of epidemic nosocomial infections. J Infus Nurs 27: 175-180.

Hamill RJ, Houston ED, Georghiou PR, Wright CE, Koza MA, Cadle RM, Goepfert PA, Lewis DA, Zenon GJ, Clarridge JE 1995. An outbreak of Burkholderia (formerly Pseudomonas) cepacia respiratory tract colonization and infection associated with nebulized albuterol therapy. Ann Intern Med 122: 762-766.

Holmes A, Govan J, Goldstein R 1998. Agricultural use of Burkholderia (Pseudomonas) cepacia: a threat to human health? Emerg Infect Dis 4: 221-227.

Jordan JA, Durso MB 2000. Comparison of 16S rRNA gene PCR and BACTEC 9240 for detection of neonatal bacteremia. J Clin Microbiol 38: 2574-2578.

Klausegger A, Hell M, Berger A, Zinober K, Baier S, Jones N, Sperl W, Kofler B 1999. Gram-type specific broad-range PCR amplification for rapid detection of 62 pathogenic bacteria. J Clin Microbiol 37: 464-466.

Klouche M, Schröder U 2008. Rapid methods for diagnosis of bloodstream infections. Clin Chem Lab Med 46: 888-908.

Loukil C, Saizou C, Doit C, Bidet P, Mariani-Kurkdjan P, Aujard Y, Beaufils F, Bingen E 2003. Epidemiological investigation of Burkholderia cepacia acquisition in two pediatric intensive care units. Infect Control Hosp Epidemiol 24: 707-710.

Madico GE, Rice PA 2008. 16S ribosomal DNA to diagnose culturenegative endocarditis. Curr Infect Dis Rep 10: 280-286.

Matrician L, Ange G, Burns S, Fanning WL, Kioski C, Cage GD, Komatsu KK 1998. Nosocomial Burkholderia cepacia infection and colonization associated with intrinsically contaminated mouthwash - Arizona, 1998. MMWR 47: 926-928.
Mitka S, Anetakis C, Souliou E, Diza E, Kansouzidou A 2007. Evaluation of different PCR assays for early detection of acute and relapsing brucellosis in humans in comparison with conventional methods. J Clin Microbiol 45: 1211-1218.

Morata P, Queipo-Ortuño MI, de Dios Colmenero J 1998. Strategy for optimizing DNA amplification in a peripheral blood PCR assay used for diagnosis of human brucellosis. J Clin Microbiol 36: 2443-2446.

Murdoch DR anderson TP, Beynon KA, Chua A, Fleming AM, Laing RT, Town GI, Mills GD, Chambers ST, Jennings LC 2003. Evaluation of a PCR assay for detection of Streptococcus pneumoniae in respiratory and nonrespiratory samples from adults with community-acquired pneumonia. J Clin Microbiol 41: 63-66.

Murty DS, Gyaneshwari M 2007. Blood cultures in paediatric patients: a study of clinical impact. Indian J Med Microbiol 25: 220-224.

$\mathrm{Ng} \mathrm{W}$, Olsen K, Lutsar I, Wubbel L, Ghaffar F, Jafri H, McCracken GH Jr, Friedland IR 2008. Buffy coat PCR for diagnosis of experimental pneumococcal pneumonia. Acta Pathol Microbiol Immunol Scand 108: 729-733.

Odetola FO, Moler FW, Dechert RE, VanDerElzen K, Chenoweth C 2003. Nosocomial catheter-related bloodstream infections in a pediatric intensive care unit: risk and rates associated with various intravascular technologies. Pediatr Crit Care Med 4: 432-436.

Parker MM, Parrillo JE 1983. Septic shock. Hemodynamics and pathogenesis. JAMA 250: 3324-3327.

Segal GS, Chamberlain JM 2000. Resource utilization and contaminated blood cultures in children at risk for occult bacteremia. Arch Pediatr Adolesc Med 154: 469-473.

Shafazand S, Weinacker AB 2002. Blood cultures in the critical care unit: improving utilization and yield. Chest 122: 1727-1736.

Thomassen MJ, Demko CA, Klinger JD, Stern RC 1985. Pseudomonas cepacia colonization among patients with cystic fibrosis. A new opportunist. Am Rev Respir Dis 131: 791-796.

Varghese B, Rodrigues C, Deshmukh M, Natarajan S, Kamdar P, Mehta A 2006. Broad-range bacterial and fungal DNA amplification on vitreous humor suspected endophthalmitis patients. Mol Diagn Ther 10: 319-326.

Weems JJ Jr 1990. Nosocomial outbreak of Pseudomonas cepacia associated with contamination of reusable electronic ventilator temperature probes. Infect Control Hosp Epidemiol 14: 583-586.

Xu J, Moore JE, Millar BC, Webb H, Shields MD, Goldsmith CE 2005. Employment of broad range 16S rDNA PCR and sequencing in the detection of aetiological agents of meningitis. New Microbiol 28: 135-143. 